\title{
Effect Of Unsaturated Fatty Acid Omega-3 On Some Histological Criteria In White New Zealand Rabbits Administrated With Cyclosporine Drug
}

\author{
Murtadha M. Jawad ${ }^{* 1}$, Wijdan Rajh Hamza Al-Kraity ${ }^{* 2}$ \\ ${ }^{1}$ College of Health and Medical Techniques / Al-Furat Al-Awsat Technical University, Al-Kufa, Iraq \\ ${ }^{2}$ Department Medical Laboratories Techniques, Al-Toosi University College, AL-Najaf, Iraq \\ *e-mail: kuh.dr.mur@atu.edu.iq , dr.wijdan_rajh@altoosi.edu.iq
}

\begin{abstract}
The present study was aimed efficiency to evaluate the unsaturated fatty acid omega-3 in reducing the side effects that resulted from administration of cyclosporine drug in white New Zealand rabbits. (60) from white males' rabbits were used in this study, the animals divided into major four groups (15) rabbits per group and its subdivision into three groups (5) rabbits per group. The first group is orally administered with normal saline, second groups were administered cyclosporine $(25 \mathrm{mg} / \mathrm{kg})$ only. Third groups were administered cyclosporine $(25 \mathrm{mg} / \mathrm{kg})$ in the first day and Omega-3 (500mg/kg) in the second day, while Fourth groups were administered cyclosporine $(25 \mathrm{mg} / \mathrm{kg})$ in the first day and omega-3 $(1000 \mathrm{mg} / \mathrm{kg})$ in the second day for periods $(21,30,60)$ days respectively. After ending study periods, the animals were sacrificed and the blood was collected and samples from liver were taken and the results were showed the following: the histological study showed pathological changes after administration of cyclosporine $(25 \mathrm{mg} / \mathrm{kg})$ with blood congestion for period (21day), while severe blood congestion with beginning of fibrosis for period (30day) while in the period (60day) very severe blood congestion with aggregation of inflammatory cells and grow of fibroblast cells were showed. while the interaction between cyclosporine and two concentrations $(500 \& 1000 \mathrm{mg} / \mathrm{kg})$ of omega-3 were showed non-pathological changes in liver tissues. From this study concluded that omega-3 have an important role in the reducing histopathology side effects that result from administration of cyclosporine drug in white rabbits.

Keywords: Omega-3, Cyclosporine Drug, Liver, Inflammatory Cells, Fibroblast Cells.
\end{abstract}

Article Information
Received: Augest 9, 2021; Revised: Augest 23, 2021; Online: September, 2021

\section{INTRODUCTION}

Cyclosporin was discovered for the first time in the seventies of the last century, Taking the isolated chance of Norwegian soil fungi called Tolypolidium inflatum by product metabolism was used as an Antifungal[1].

The drug consists of a multi-cyclic peptide consisting of eleven amino acid, which hydrophobic can be dissolved in organic solvent, where available in several a commercial form of capsules, oral, syrup, and injection mixed with castor oil which is considered the best organic solvent for the drug[2].

Cyclosporine is a drug used in the treatment of patients with organ transplants since the eighties, having observed that has the potential to inhibit the body's natural immunity and thus not to reject the transplanted organ[3].

Cyclosporine has become a backbone in inhibiting the body's immune system in the treatment of patients with organ transplants, 
cyclosporine is also used in the treatment of autoimmune diseases such as rheumatoid arthritis, psoriasis and skin infections[4].

The drug effect on the T-Lymphocytes and prevents its function, where the drug is linked to its receptors on lymphocytes is associated with cyclophilin to prevent phosphorylation calcineurine process and thereby preventing nuclear factor of activated T-cell and translate of mRNA to build interleukin-2 to activate the body's immune[5].

The drug Gelatinous capsules dissolve the intestines absorb incompletely small intestine varies individually, metabolizes the drug extensively in the liver and eliminate mainly through the bile into the feces and about $6 \%$ of it with lactation and $1 \%$ raises unchanged[6].

Although uses extensive The drug, but it has side effects may be harmful, such as high blood pressure, liver toxicity, kidney toxicity, and at least effects common and rare vomiting, nausea, tingling of the parties and the legs and the sensitivity and increased hair growth on the face, back and chest, enlarged gums and the patient exposed to infections opportunistic[7].

The fatty acid omega-3 fatty acids are one of unsaturated and which are essential to the body's inability to build. Omega -3 has a double bond between two atoms of the third and fourth carbon from the end methylation[8]-[10].

For omega-3 health benefits multiple, so the meal is rich in omega -3 be associated with reduced heart disease and inflammation and an increase in the effectiveness of reproduction, vision and treatment of diseases of the joints, scabies, ulcers colon Add in percentage role in reducing the severity of cancer[8]-[15].

Therefore, this study was conducted to investigate the role of omega- 3 in reducing side effects when treated with a drug cyclosporine, which included: the study of histological changes in the liver.

\section{MATERIALS AND METHODS Laboratory Animals}

The total animal study (60) White New Zealand rabbit and male only, weights ranged from $(1200-1500 \mathrm{~g})$, and between the ages of (10-12 months), were obtained animals from Animal House / College of Veterinary Medicine / University of Kufa. The study began 15/06/2021-15/09/2021. Leave the animals in the animal house and under the standard conditions of temperature and (13hour day and 11 hour) overnight and fed well for the duration of the experiment.

\section{Preparation of study materials: Preparation of omega-3:}

Omega-3 is available concentration of the $(500 \& 1000 \mathrm{mg} / \mathrm{kg})$ in Gelatne capsules, obtained from the company (Novartis) and given to the male rabbits at oral depending on the animal's weight per day[16].

Preparation of cyclosporine drug:

Drug cyclosporine is available concentration $(25 \mathrm{mg} / \mathrm{kg})$ in Gelatneh capsules, obtained from the company (T\&D pharma Gmbh) and was given a dose of male rabbits at oral daily depending on the animal's weight[17].

\section{Animals Sacrificing:}

Male rabbits were sacrificed after anesthesia by the ether in the days $(61,31,22)$ for groups treated orally Periods $(60,30,21)$ day in a respectively. After that, open the abdominal cavity and removal of organs (liver) and weighed by a sensitive balance type (Sartorins). And put organs in $10 \%$ formalin solution for fixation until the work of histological sections and staining by EosinHematoxylin and examination under the microscope.

\section{Preparation of Histology:}

Preparation of histological sections using the method of Levison, 1997 [18], fixed samples by formalin (10\%) and then several steps performed include (drying, clarification, hydration, imbedding, cutting, staining, and examination).

\section{Statistical Analyses:}

Statistical analyses including survival and multivariate analyses of factors associated with survival were respectively performed by Kaplan-Meier method and Cox proportional hazard model.[19]. 


\section{RESULT}

The effect of a drug cyclosporine concentration $(25 \mathrm{mg} / \mathrm{kg})$ for different time periods in the liver tissue.

Indicate histological images (1),(3),(5),(7) and (9) to the presence of changes in the liver after treatment with a drug cyclosporine concentration $(25 \mathrm{mg} / \mathrm{kg})$ were represented congestion bloody in the picture (1) when the concentration of cyclosporine-term basis (21 days), while the most changes in the duration of treatment (30 days) and was the bloody

severe congestion with the onset of cirrhosis of the image (3). either drug treatment period (60 days) represented changes occurrence blood congestion and the presence of inflammatory cells, as in the picture (5) are collected inflammatory cells and congestion is very severe bloody in the image (7) either image (9) was very clear changes occurrence chronic inflammatory cells collect with the growth of Fibroblast cells in the region pylori.

The interaction effect between the concentration of cyclosporine $(25 \mathrm{mg} / \mathrm{kg})$ and concentrative $(500 \& 1000 \mathrm{mg} / \mathrm{kg})$ of omega3 and for different time periods in the liver tissue.

Show images (2), (4), (6), (8) and (10) were not affected liver tissue after the interference between drug and the concentration of omega- 3 and all the periods (21 days), (30 day) and (60 days) compared with the control group portrait (11)
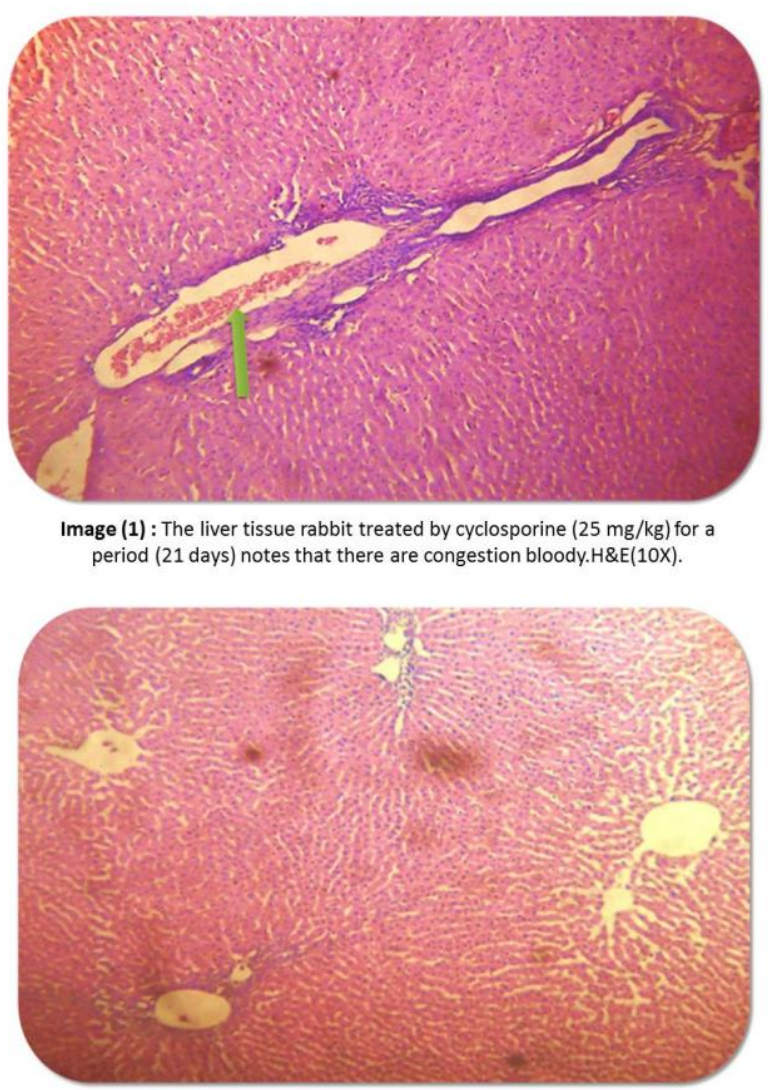

Image (2) : The liver tissue of rabbit treated by cyclosporine $(25 \mathrm{mg} / \mathrm{kg})$ and omega-3 $(500 \mathrm{mg} / \mathrm{kg}$ ) for a period ( 21 days) notes were not affected tissue.
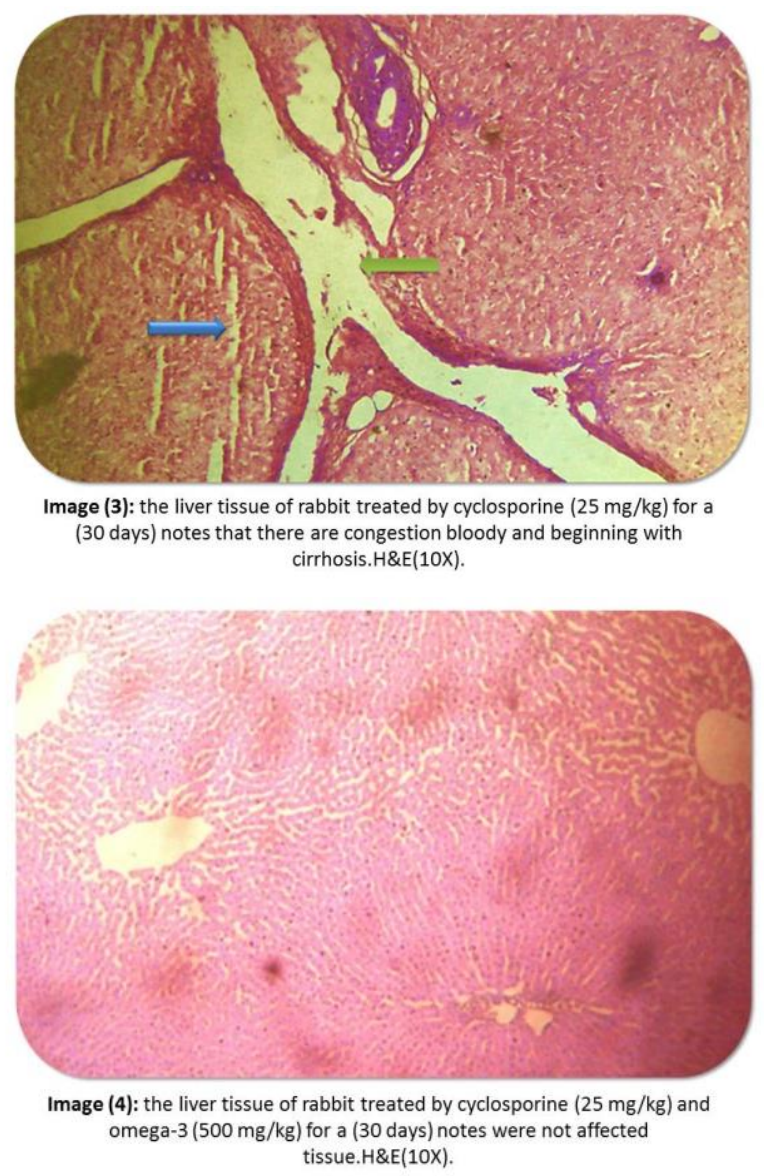


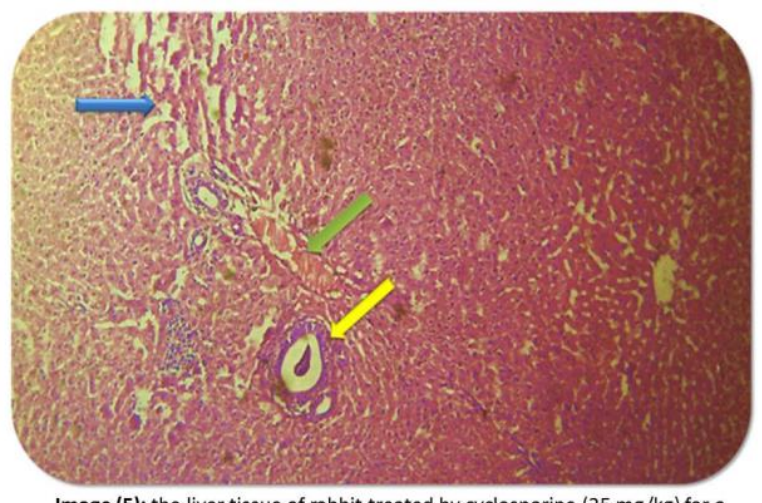

Image (5): the liver tissue of rabbit treated by cyclosporine $(25 \mathrm{mg} / \mathrm{kg})$ for a (60 days) notes that there are congestion bloody, inflammation cell and beginning with cirrhosis. $\mathrm{H} \& \mathrm{E}(10 \mathrm{X})$.

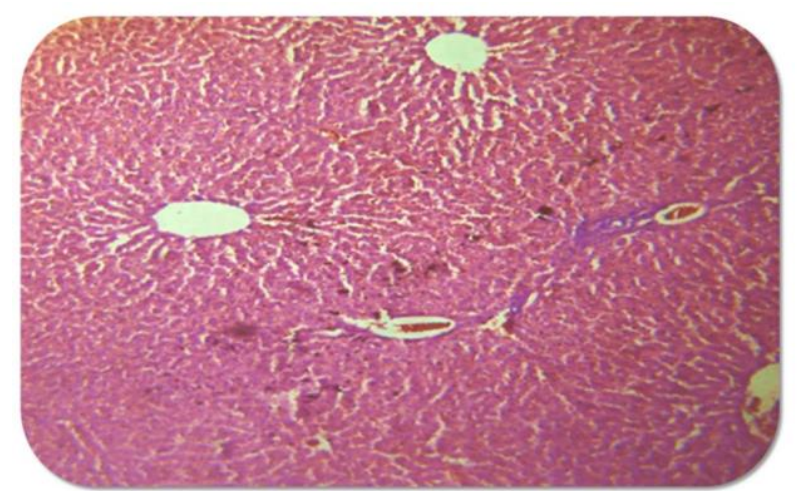

Image (6): the liver tissue of rabbit treated by cyclosporine $(25 \mathrm{mg} / \mathrm{kg})$ and omega-3 $(500 \mathrm{mg} / \mathrm{kg}$ ) for a (60 days) notes were not affected tissue. H\&E(10X).

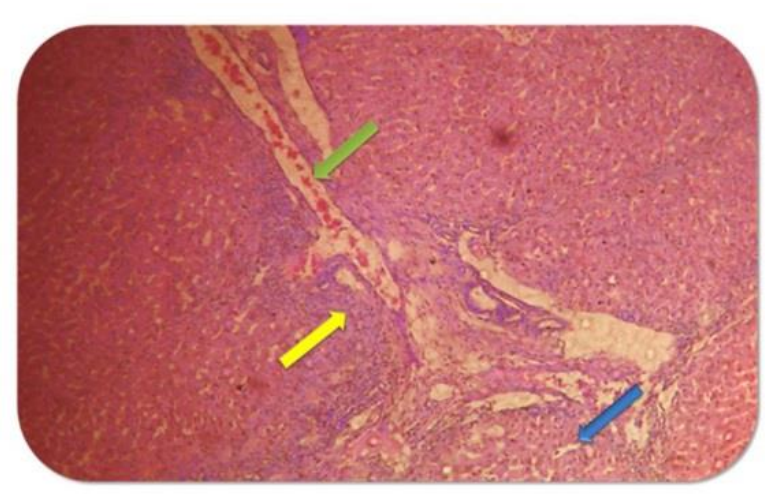

Image (7): the liver tissue of rabbit treated by cyclosporine $(25 \mathrm{mg} / \mathrm{kg})$ for a ( 60 days) notes that there are congestion bloody, inflammation cell and moderate cirrhosis. H\&E(10X).

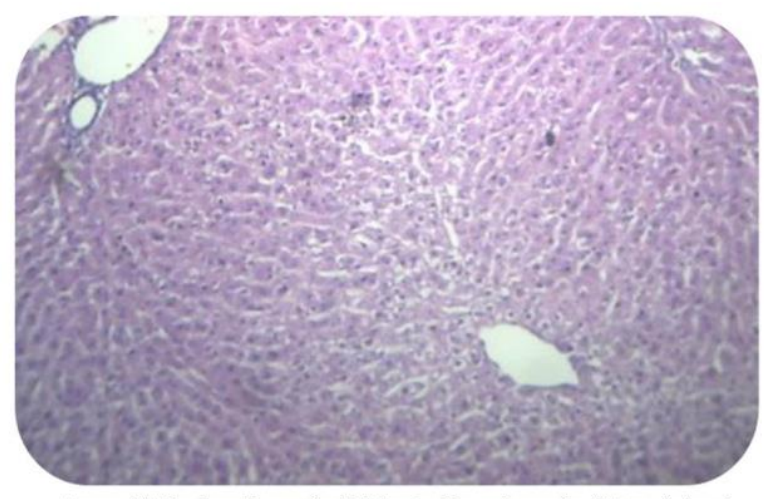

Image (8): the liver tissue of rabbit treated by cyclosporine $(25 \mathrm{mg} / \mathrm{kg})$ and omega-3 $(1000 \mathrm{mg} / \mathrm{kg}$ ) for a (30 days) notes were not affected tissue. H\&E(10X).

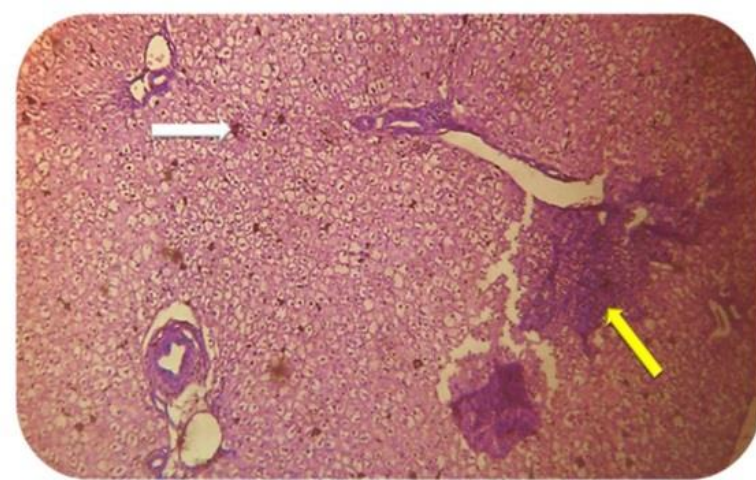

Image (9): the liver tissue of rabbit treated by cyclosporine $(25 \mathrm{mg} / \mathrm{kg})$ for a (60 days) notes that there are aggregation of inflammation cell and with firoblast appears. H\&E(10X).

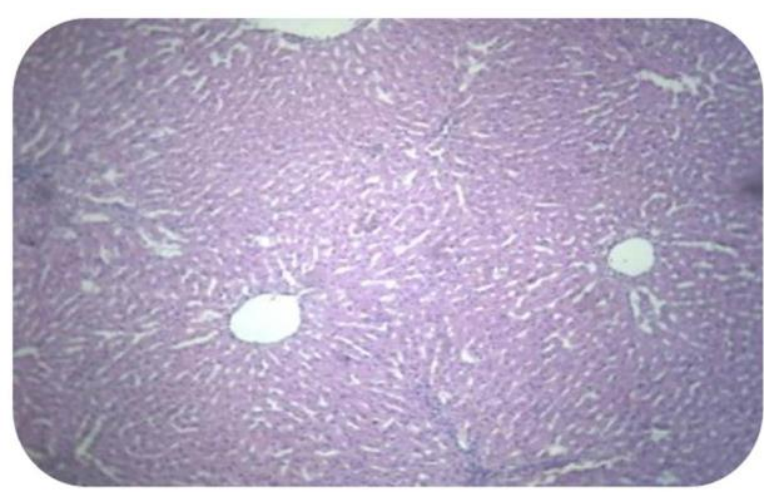

Image (10): the liver tissue of rabbit treated by cyclosporine $(25 \mathrm{mg} / \mathrm{kg})$ and omega-3 $(1000 \mathrm{mg} / \mathrm{kg}$ ) for a (60 days) notes were not affected tissue.H\&E(10X).

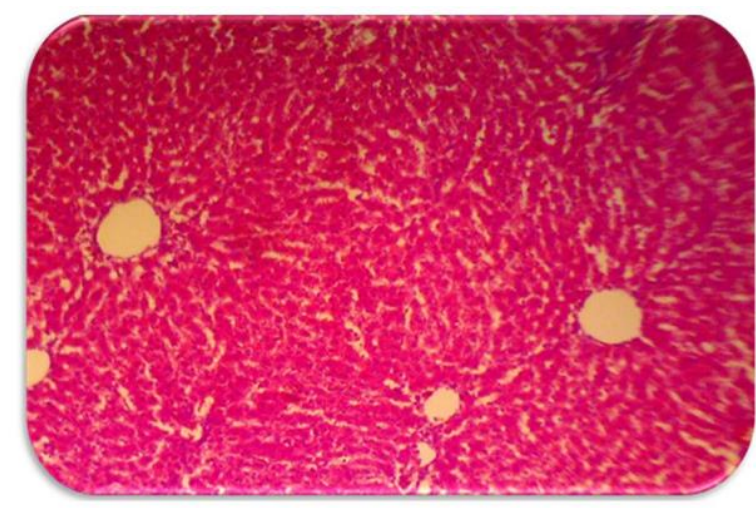

Image (11): the liver tissue of rabbit control groups.H\&E(10X).

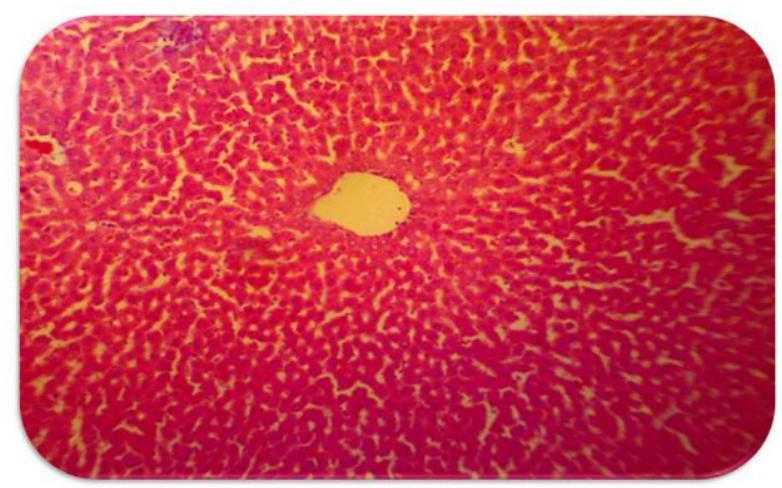

Image (12) : The liver tissue of rabbit treated by cyclosporine $(25 \mathrm{mg} / \mathrm{kg})$ and omega-3 $(1000 \mathrm{mg} / \mathrm{kg}$ ) for a period ( 21 days) notes were not affected tissue. 


\section{DISCUSSION}

\section{Histological changes in the liver tissue before and after interference drug cyclosporine with omega-3:}

Results from the current study, the occurrence histological changes visible in liver tissue consisted inflammatory cells and blood congestion, which has increased with the progress of treatment cyclosporine duration and increasing possible dose to explain the result on the basis of the toxic potential liver Hepatoxicity[20].

The presence of inflammatory cells in the liver tissue may be associated with the inhibition of lymphocyte type (T) by cyclosporin and this may work to the increase in collect of the inflammatory cells and accumulate whenever treatment for increased dose This is indicated by numerous studies[21]-[23].

Cyclosporine has been working to increase oxidative stress and increase the types of Reactive oxygen Species (ROS) within the liver tissue such as $(\mathrm{OH}, \mathrm{O}-, \mathrm{H} 2 \mathrm{O} 2)$ accompanied by a reduction in the enzyme Catalase and Glutathione peroxidase with increased Malondialdehyde and lead to an increase in Lipid peroxidation process and this process may lead to Vasoconstriction and clot blood[24]. This has been demonstrated in the results of the current study, the occurrence of bloody tissue congestion in the liver tissue.

I found research that the drug cyclosporine in addition to the caused the increase in the fat composition of the process is an important factor in causing harm to tissue of the liver, kidney and heart, as well as an important factor in stimulating Lipid peroxidation process and an increase in the accumulation of free radicals within the tissue[25]-[27].

It may explain the increase in the types of free radicals within the tissue liver caused as a result of an increased oxidative phosphorylation to mitochondria and the accompanying increase in the electron transport chain, which leads to the accumulation of these free radicals within the liver tissue and kidney in addition to generating these roots through metabolism Cytochrom P-450 and these processes are associated with a reduction in Antioxidative system and especially the enzyme Catalase and Glutathione peroxidase (GP) and as a result harmful influence of the tissues of the liver and kidney happens[28]-[30].

All of the results of histological images especially of the liver the interference of drug cyclosporine with omega-3 led to the cancellation of the harmful effect of cyclosporine and non-affected tissue when compared with the control group.

This result is possible that due to the possession of omega-3 to increase the viability to efficiency of the anti-oxidant system and suppress of all free radicals within the body before attacking tissue This indicated by a study[31].

Omega -3 may work to inhibit Lipid peroxidation process which increases the effectiveness of the enzyme's catalase and Glutathione peroxidase[32].

The effectiveness of omega- 3 may lie in preventing the increase perfusion membraneand especially liver tissue with enzymes to increase membrane stabilization to prevent perfusionions of electrolytes and water with the organization in the balance of internal calcium ions and which plays an important role in the toxicity of cyclosporine[33].

The effect of omega-3 Antiinflammation may have a role in preventing inflammatory cells collected and stimulating $\mathrm{T}$ lymphocytes, resulting in the absence of any inflammation of the tissue in the liver after interference drug cyclosporine and omega$3[34]$.

\section{CONCLUSION}

From this study concluded that omega-3 have an important role in the reducing Histopathology side effects that result from administration of cyclosporine drug in white rabbits.

\section{REFERANCE}

[1] K. E. Bushley et al., "The Genome of Tolypocladium inflatum: Evolution, Organization, and Expression of the Cyclosporin Biosynthetic Gene Cluster," PLoS Genet., 2013, doi: 10.1371/journal.pgen.1003496. 
[2] G. S. Baarsma and L. Caspers, "Cyclosporin A," in Intraocular Inflammation, 2016.

[3] S. Nkongolo et al., "Cyclosporin A inhibits hepatitis B and hepatitis D virus entry by cyclophilin-independent interference with the NTCP receptor," J. Hepatol., 2014, doi: 10.1016/j.jhep.2013.11.022.

[4] A. H. de Wilde et al., "Cyclosporin A inhibits the replication of diverse coronaviruses," J. Gen. Virol., 2011, doi: 10.1099/vir.0.034983-0.

[5] D. Stevenson, J. Tauber, and B. L. Reis, "Efficacy and safety of cyclosporin A ophthalmic emulsion in the treatment of moderate-to-servere dry eye disease: A dose-ranging, randomized trial," Ophthalmology, 2000, doi: 10.1016/S0161-6420(00)00035-X.

[6] C. Emilienne Soma, C. Dubernet, D. Bentolila, S. Benita, and P. Couvreur, "Reversion of multidrug resistance by coencapsulation of doxorubicin and cyclosporin A in polyalkylcyanoacrylate nanoparticles," Biomaterials, 2000, doi: 10.1016/S0142-9612(99)00125-8.

[7] W. Y. Lim, C. M. Messow, and C. Berry, "Cyclosporin variably and inconsistently reduces infarct size in experimental models of reperfused myocardial infarction: A systematic review and metaanalysis," British Journal of Pharmacology. 2012, doi: 10.1111/j.1476-5381.2011.01691.x.

[8] A. P. Simopoulos, "The importance of the ratio of omega-6/omega-3 essential fatty acids," Biomed. Pharmacother., 2002, doi: 10.1016/S07533322(02)00253-6.

[9] B. Cassileth, "Omega-3," Oncology, 2010, doi: 10.18508/endo2991.

[10]A. P. Simopoulos, "Omega-3 fatty acids in inflammation and autoimmune diseases," J. Am. Coll. Nutr., 2002, doi: 10.1080/07315724.2002.10719248.

[11]A. P. Simopoulos, "Evolutionary aspects of diet: The omega-6/omega-3 ratio and the brain," Mol. Neurobiol., 2011, doi: 10.1007/s12035-010-8162-0.
[12]A. Gupta, C. J. Barrow, and M. Puri, "Omega-3 biotechnology: Thraustochytrids as a novel source of omega-3 oils," Biotechnology Advances. 2012 , doi: 10.1016/j.biotechadv.2012.02.014.

[13]P. C. Calder, "Omega-3 fatty acids and inflammatory processes," Nutrients. 2010, doi: 10.3390/nu2030355.

[14]A. P. DeFilippis and L. S. Sperling, "Understanding omega-3's," American Heart Journal. 2006, doi: 10.1016/j.ahj.2005.03.051.

[15]T. C. Adarme-Vega, D. K. Y. Lim, M. Timmins, F. Vernen, Y. Li, and P. M. Schenk, "Microalgal biofactories: a promising approach towards sustainable omega-3 fatty acid production," Microbial Cell Factories. 2012, doi: 10.1186/1475-2859-11-96.

[16]M. M. Jawad, "Effect of Unsaturated Fatty Acid Omega-3 on Some Biochemical Criteria in White New Zealand Rabbits Administrated with Cyclosporine Drug," Med. Sci. J. Adv. Res., vol. 2, no. 1, pp. 15-24, 2021, doi: 10.46966/msjar.v2i1.14.

[17]M. M. Jawad, "Relationship Between Hepatotoxicity That Induced by CCL4 and Regucalcin Protein Marker," Med. Sci. J. Adv. Res., vol. 2, no. 2, pp. 35-44, 2021, doi: 10.46966/msjar.v2i2.17.

[18]D. A. Levison, "Book Reviews :Theory and practice of histological techniques. 4th Edition. JOHND. BANCROFT and ALAN STEVENS. Churchill Livingstone, Edinburgh. 1996 No. of Pages: 766 Price £79.50,” J. Pathol., 1997, doi: 10.1002/(sici)10969896(199710)183:2<243::aidpath770>3.0.co;2-f.

[19]J. Stull, "SPSS for Windows," Teach. Sociol., 1994, doi: 10.2307/1318629.

[20]D. Phillips, A. R. Deipolyi, R. L. Hesketh, M. Midia, and R. Oklu, "Pelvic congestion syndrome: Etiology of pain, diagnosis, and clinical management," Journal of Vascular and Interventional Radiology. 2014, doi: 10.1016/j.jvir.2014.01.030. 
[21]F. Tacke, T. Luedde, and C. Trautwein, "Inflammatory pathways in liver homeostasis and liver injury," Clinical Reviews in Allergy and Immunology. 2009, doi: 10.1007/s12016-008-8091-0.

[22]A. Hoshino et al., "Tumour exosome integrins determine organotropic metastasis," Nature, 2015, doi: 10.1038/nature15756.

[23]F. Heymann and F. Tacke, "Immunology in the liver-from homeostasis to disease," Nature Reviews Gastroenterology and Hepatology. 2016, doi: 10.1038/nrgastro.2015.200.

[24] A. Ayala, M. F. Muñoz, and S. Argüelles, "Lipid peroxidation: Production, metabolism, and signaling mechanisms of malondialdehyde and 4-hydroxy-2nonenal," Oxidative Medicine and Cellular Longevity. 2014, doi: 10.1155/2014/360438.

[25]C. Mylonas and D. Kouretas, "Lipid peroxidation and tissue damage," In Vivo. 1999.

[26] T. P. A. Devasagayam, K. K. Boloor, and T. Ramasarma, "Methods for estimating lipid peroxidation: An analysis of merits and demerits," Indian Journal of Biochemistry and Biophysics. 2003.

[27] Y. Xie et al., "Ferroptosis: Process and function," Cell Death and Differentiation. 2016, doi: 10.1038/cdd.2015.158.

[28]G. Silling, "Fluconazole: optimized antifungal therapy based on pharmacokinetics.," Mycoses. 2002, doi: 10.1111/j.1439-0507.2002.tb04768.x.

[29]G. Bayramoglu, B. Filiz Senkal, M. Yilmaz, and M. Yakup Arica,
"Immobilization and stabilization of papain on poly(hydroxyethyl methacrylate-ethylenglycol

dimethacrylate) beads grafted with epoxy functional polymer chains via surfaceinitiated-atom transfer radical polymerization (SI-ATRP)," Bioresour. Technol., 2011, doi: 10.1016/j.biortech.2011.08.042.

[30]D. Domaradzka, U. Guzik, and D. Wojcieszyńska, "Biodegradation and biotransformation of polycyclic nonsteroidal anti-inflammatory drugs," Reviews in Environmental Science and Biotechnology. 2015, doi: 10.1007/s11157-015-9364-8.

[31]G. M. Cole, Q. L. Ma, and S. A. Frautschy, "Omega-3 fatty acids and dementia," Prostaglandins Leukot. Essent. Fat. Acids, 2009, doi: 10.1016/j.plefa.2009.05.015.

[32]S. S. Gill and N. Tuteja, "Reactive oxygen species and antioxidant machinery in abiotic stress tolerance in crop plants," Plant Physiology and Biochemistry. 2010, doi: 10.1016/j.plaphy.2010.08.016.

[33]T. Dodd-Butera and M. Broderick, "Cyclosporine," in Encyclopedia of Toxicology: Third Edition, 2014.

[34]N. Rubio-Rodríguez, S. Beltrán, I. Jaime, S. M. de Diego, M. T. Sanz, and J. R. Carballido, "Production of omega-3 polyunsaturated fatty acid concentrates: A review," Innovative Food Science and Emerging Technologies. 2010, doi: 10.1016/j.ifset.2009.10.006. 